\title{
PORTO ALEGRE: \\ DOS CINEMAS, CAFÉS, JORNAIS, \\ LIVRARIAS E PRAÇAS \\ A CAPITAL DOS LIVROS (1929-1948)
}

Elizabeth Wendhausen Rochadel Torresini*

Nas décadas de 30 e 40, há em Porto Alegre uma movimentada vida cultural. Nas ruas centrais, podem ser encontrados locais de lazer, de debates e de produção de cultura. Na emblemática Rua da Praia, o centro difusor do mundo dos negócios e da política, circulam os visitantes e os habitantes da cidade.

Augusto Meyer recordando a Rua da Praia no livro No tempo da flor, afirma que esta rua foi "a estrada real da nossa formação". A sua Rua da Praia e de tantos intelectuais, seus contemporâneos, é apresentada como a "sala de visitas da capital" que nessa década de 20 ainda carrega o provincianismo do século XIX. Ali as pessoas se encontram, discutem o futuro da Nação e marcam a identidade da capital do Rio Grande do Sul.

Pode-se descrever a identidade de Porto Alegre pelos cinemas. Augusto Meyer lembra com muito carinho do Cinema Ideal, cujo proprietário era um tio de Athos Damasceno Ferreira. Recorda ainda o nome de outros, como o Smart-Salão, o Variedades, o Avenida, o Odeon, o Petit-Cassino, o Guarani e o Central.

"(...) O Petit-Cassino era um cine-teatro que se tornou logo famoso pelo barroquismo delirante de sua fachada. De cada lado dessa heteróclita fachada, lá no alto, dois cavalheiros encartolados pareciam espreitar -se, indiscretos, como quem ainda não acabou de

* Professora do Departamento de História, Instituto de Filosofia e Ciências Humanas da PUCRS.

Estudos Ibero-Americanos. PUCRS, v.XXI, n.1, p. 5-18, julho, 1995 
abotoar a braguilha. Bem entendido, os cinemas eram mudos, mas a nossa gárrula imaginação falava por eles, assobiava e cantava por eles, e com mais harmonia do que as orquestrinhas. É a lei das compensações. Pobres meninos e moços nascidos no tempo da pedra lascada, não tínhamos televisão, nem rádio, nem cinema sonoro. O nosso desenho animado era uma inqualificável lanterna mágica, um reles cosmorama. Em compensação, como tudo era tímido e racionado, não sofríamos de fartura, com poucos foguetes a fantasia armava a sua festa". (Meyer, 1966, p. 126)

Ou pode-se descrever a identidade de Porto Alegre por seus jornais. Os mais importantes do estado também ficam na Rua da Praia e imediações. O Correio do Povo e A Federação estão na mesma fronteira e um pouco mais adiante o Diário de Notícias. Dentro das redações desses jornais muitos escritores iniciam sua carreira literária.

Nas décadas de 20 e 30, segundo a memória de Augusto Meyer e Paulo de Gouvêa, os bares são parte importante desse cenário chamado Rua da Praia. O ponto obrigatório de encontro dos intelectuais porto-alegrenses é o Café Colombo, passo inicial do subseqüente itinerário noturno.

O Café Colombo situa-se na esquina da Rua General Câmara com a Rua da Praia. Na área térrea, que possui frente para as duas ruas, são colocadas mesinhas de mármore para delícia dos freqüentadores. Segundo Paulo de Gouvêa, os "(...) fregueses eram todos de caderno e tão habituais que a maioria deles tinha mesa cativa e, até, horário de entrada e de saída (...)". (Gouvêa, 1976, p. 18)

Além do andar térreo há uma galeria no andar de cima que circunda o salão onde a orquestra do maestro Radamés Gnattali toca valsas, tangos, foxes.

Do itinerário noturno constam os "bebedouros famosos" da Idade de Ouro boêmia, como a chamou Augusto Meyer: o Chalé da Praça XV, o Eduardo, o Zitter Franz, o Binter, o Antonello e outros.

Zitter Franz ocupa uma velha casa na subida da Rua da Praia e ali serve-se quase que exclusivamente chopp e cerveja. Paulo de Gouvêa lembra o Zitter como um dos prediletos de sua geração que costumava freqüentar aquele bar para ouvir seu proprietário - Zitter Franz - tocar à cítara velhas canções alemãs.

Ao lembrar do Chalé da Praça XV, antes de sua sofisticada reedição, Paulo de Gouvêa destaca a existência de uma orquestra de apenas três músicos que ali tocava todas as noites. Comenta com humor: 
"Terminado o número musical, Heinz vinha para a nossa mesa e, quase sempre, fechava o chalé, saía com a turma, de que era tão amigo como era do chopp, rumo ao Eduardo, ou a outro qualquer bar que ainda estivesse aberto depois da meia noite. A orquestra do Chalé embora liliputiana, tocava tudo, porque, se me permitirem o 'nonsense', maior do que sua pequenez era o seu peito: Tristão e Isolda, Chopin, Beethoven, entreverado com a lânguida 'Grossmütterchen', ou com a épica 'Carga da Cavalaria Ligeira', de Soppé. Apesar da nossa insistência, ele jamais quis executar a grande marcha patriótica 'Die Wacht am Rhein", coisa aliás que a gente bem podia compreender (...)"(Meyer, 1966 87-58).

Com exceção do Chalé da Praça XV nenhum desses "bebedouros famosos" existem atualmente, como tampouco existem as livrarias com seus livros expostos nas vitrinas, que seduziam tanta gente.

A Livraria Americana é, nesta época, uma importante casa editorial, e seus donos primitivos, Pinto \& Cia., "(...) inscrevem-se no rol dos raros pioneiros da edição de livros no Rio Grande do Sul. Por anos a fio, publicaram eles, com bastante regularidade (fato excepcional naqueles tempos em terras gaúchas), obras de diferentes gêneros literários, inclusive uma coleção de romances em formato livro de-bolso". (Gouvêa, 1976, p. 25)

Na década de 20, Porto Alegre já conta com importantes livrarias, além da Americana, destacando-se aquelas freqüentadas pelos intelectuais e localizadas na zona central da cidade.

A Livraria Selbach \& Cia., fundada em 1908, trabalha com material para escritório, papelaria, encadernação, pautação, cartonagem, objetos de culto, miudezas e máquinas de costura. Em 1945 é citada como importante editora de livros escolares, sendo suas edições adotadas no Rio Grande do Sul, Santa Catarina, Paraná, São Paulo, Rio de Janeiro, Minas Gerais, Espírito Santo e Bahia. Emprega, nesta época, 35 empregados sendo 21 homens e 14 mulheres e vende mercadorias importadas da Alemanha, França, Inglaterra, Áustria, Itália e Suíça. A Livraria Selbach situava-se na Rua Marechal Floriano n 92 e 94 (Pimentel, 1945, p. 339).

Anuário do Estado do Rio Grande do Sul para o ano de 1914 de Graciano A. de Azambuja. Porto Alegre, Editores Krahe e Cia. Sucessores de Giundlach \& Krohe, 1913, p. 330.

Na mesma Marechal Floriano encontrava-se a Livraria de João Mayer Filho com papelaria, objetos de escritório e livros de devoção em 
diversos idiomas. Possuía o maior sortimento de artigos religiosos e objetos para igreja, o que liga a colégios católicos. Segundo Paulo de Gouvêa "(...) sua maior clientela compunha-se de estudantes do Anchieta, do Sevigné, do Bom Conselho e do Colégio (fechado há muito tempo) da Professora Cecília Corseuil Du Pasquier". (Gouvêa, 1976, p. 94)

A Livraria de João Mayer Filho, apesar de sua significativa clientela, não se dedicava a edição de livros e nenhuma referência a este respeito foi encontrada.

Na Rua Dr. Flores ficava a Livraria Commercial que se dedicava também à encadernação, douração e pautação. Trabalhava com livros comerciais, feitos por encomenda em suas oficinas, mas a exemplo da livraria de João Mayer Filho a Commercial não se dedicava a edições.

O Estabelecimento Typographico de Germano Gundlach \& Cia., que se situava na Rua General Vitorino, editava o jornal publicado em alemão Neue Deutsche Zeitung, além de fabricar nitidamente todos os trabalhos comerciais como circulares, contas, recibos, relatórios, convites para enterros etc. Possuía todo o sortimento de materiais para o comércio.

E na Rua da Praia achavam-se duas outras livrarias a Central e a Universal. A Livraria Central fabricava livros em branco e dedicava-se à encadernação, pautação e douração, além de ser, em Porto Alegre, agente de jornais de modas, literários e científicos. Trabalhava com jornais nacionais e estrangeiros e possui uma filial na Rua Duque de Caxias.

Por último, a livraria Universal de Carlos Echenique é assim apresentada por Paulo de Gouvêa:

"(...) Era um edifício estreito, tanto que dispunha de apenas duas portas, uma das quais aproveitada como vitrina onde, semanalmente, eram expostas as novidades que aqui aportavam vindas da Europa, principalmente, e do Rio. E como eram baratos os livros populares - por isso mesmo de grande público - que na sua maioria nos chegavam de Portugal, de envolta com os de Eça de Queirós, Joâo Grave, que era colaborador do Correio do Povo, do brasileiro Coelho Neto, do notável e esquecido Camilo Castelo Branco, a fora as traduções dos grandes nomes da literatura européia (...) 
Guardo da Livraria do Echenique uma recordação bem viva e que remonta aos meus tempos anchietanos. É que meu companheiro de banco escolar era Carlos Echenique, filho do dono da livraria, em cuja companhia ali fui comprando os almanaques atrasados do Graciano Azambuja (a duzentos réis). Foi na pequena vitrina que vi exposto o primeiro número da revista Eu Sei Tudo (título traduzido da Parisiense 'Je Sais Tuot') e que acabava de sair no Rio de Janeiro, iniciando uma carreira que se prolongou por mais de 40 anos, até que caiu vencida pela concorrência das modernas e belas revistas que hoje lemos" (Gouvêa, 1976, p. 23-24)

Toda a cidade tem seus bares, cinemas, livrarias, casas de comércio. Tem, ainda, a gente que se movimenta nesses e noutros espaços consagrados da cidade em busca de lazer, sobrevivência e de satisfação de infinitos anseios.

Toda a cidade tem seus intelectuais que são orgânicos a ela como são os bares, os cinemas, as livrarias. Os intelectuais que pensam a cidade e a refletem de uma forma diferente do resto da população, porque acabam transformando a cidade em memória. Através deles a cidade ganha história e torna-se livro, quadro, cinema, teatro, música.

Quem nos legou a Porto Alegre das décadas de 20 e 30? Mapeamento difícil.

Olyntho Sanmartin, num depoimento transcrito por Paulo de Gouvêa, chama a geração de intelectuais mais atuantes daquelas duas décadas de "Grupo do Café Colombo".

O Grupo do Café Colombo parece ter sido precedido por outro grupo que Walter Spalding chama de "Grupo dos Poetas da Praça da Harmonia" e que

"(...) compunha-se principalmente, de alguns da velha guarda e outros da mais jovem, com Zeferino Brasil, Augusto de Souza Júnior, José Picorelli, Pedro Velho e, entre outros, os ainda mais jovens, da geração de novecentos a novecentos e dois, como Augusto Meyer, Athos Damasceno, Ernani Fornari e muito mais, poetas, jornalistas, teatrólogos, contistas e cronistas (...) A brilhante plêiade que brilhou, tendo ao longe Álvaro Moreyra, até 1920 a 1922 à extinção da praça em 1924 (...)" (Spalding, 1969, p. 24)

Ao Grupo da Praça da Harmonia pode-se acrescentar Marcelo Gama, Souza Lobo, Roque Callage, Alcides Maya, Isolino Leal, Alceu Wamosy, entre outros. É provável que a Praça da Harmonia não tenha sido freqüentada habitualmente por todos os intelectuais mencionados. 
Eles foram reunidos num determinado grupo pela sua contemporaneidade.

Do Grupo do Café Colombo fazia parte: Augusto Meyer, Moisés Vellinho, Viana Moog, Darci Azambuja, Theodomiro Tostes, Ernani Fornari, Athos Damasceno Ferreira, João Santana, João Manuel de Azevedo Cavalcanti, Mário Quintana, Leônidas Garcez, Ruy Cirne Lima, Dámaso Rocha, Raul Bopp, Major Guerreiro, Vargas Neto, Aluísio Franco, Paulo Correia Lopes, Paulo de Gouvêa, Sérgio de Gouvêa e Dante de Laytano.

Esse Grupo até 1923 pode ser considerado inédito com exceção de Augusto Meyer que publica neste ano seu primeiro livro de poemas $A$ Ilusão Querida. Em 1926 Meyer já possui outro livro publicado, Coração Verde.

Em 26, João Manuel de Azevedo Cavalcanti, o Jean des Rues, cronista social do Diário de Notícias, sugere a criação de uma revista literária, idéia que é recebida pelo grupo com toda a reserva, mas João Cavalcanti "tanto insistiu, tanto batalhou, que saiu vencendo". A Revista Madrugada, como é batizada, vive de setembro a dezembro de 1926. Sobre ela Gouvêa afirma:

"Madrugada tinha vários diretores: Augusto Meyer, Theodomiro Tostes, Joāo Santana, Miranda Netto. A parte artística, e isso é intuitivo, pertencia a Sotero Cosme. Outra coisa óbvia a parte comercial ao J.M. Era impressa nas oficinas da Escola de Engenharia. Um primor gráfico, digam o que disserem, inclusive o gênio do modernismo - o senhor Alcântara Machado - (vocês conhecem esse nome?) que a tacham de 'revisteca'. Pois essa 'revisteca' foi a mais bem feita, a mais perfeita que até hoje se imprimiu no Rio Grande do Sul.

Não fiz parte da sua vanguarda. Colaborei apenas no seu n⿳2 3 , com 'O Poema da Raça'. E por aí me fiquei. Em compensação, todos os grandes nomes daquela geração privilegiada a procuraram para levar-lhe, com seu aplauso, versos que compunham e páginas em prosa inéditas até aquela hora. Querem nomes? Raul Bopp, Rui Cirne Lima, Vargas Netto, Alcides Maya, Guilherme de Almeida, Athos Damasceno Ferreira, Nogueira Leiria, Olmiro Azevedo, Pedro Vergara e o Pessoal todo do grupo". (Gouvêa, 1976, p. 51).

Em dezembro de 1926 é editado o último número de Madrugada. Anteriormente, em 1925, Darcy Azambuja publica No Galpão, obra que 
revela a tendência regionalista da literatura rio-grandense, e vem acompanhada no mesmo ano por outras publicações de igual tendência como Pampa de João Maia e Tropilha Crioula de Vargas Neto.

Entre 1926 e 1932 o Grupo do Café Colombo sai do ineditismo. São publicados livros de Ruy Cirne Lima (Minha Terra e Colônia Z e outros poemas); três novos de Augusto Meyer (Coração Verde, Poemas de Bilu e Giraluz e Sorriso Interior);Ernani Fornari (Trem da Serra); Vargas Netto (Joá, Gado Xucro e Tu); Athos Damasceno (Poemas do Sonho e da Desesperança e Lua de Vidro) Dyonélio Machado (Um Pobre Homem); de Souza Júnior (Castelo dos Fantasmas e Juca Ratão Hidrófobo); Manoelito de Ornellas (Rodeio de Estrelas e Arco-Íris); Theodomiro Tostes (Novena à S. Das Graças e Bazar); Telmo Vergara ( $\mathrm{Na}$ Platéia e O Moço que Via Demais); Raul Bopp (Cobra Norato); Pedro Wayne (Versos Meninosos e A Lua); Paulo Correa Lopes (Poemas de Mim Mesmo e Caminhos); Dante de Laytano (Uma Mulher e Outras Fatalidades), Paulo de Gouvêa (Mansamente); entre outras obras menos conhecidas. Em 1932 Érico Veríssimo publica seu primeiro livro de contos Fantoches.

Esses autores gaúchos até pelo menos 1930 residem no Rio Grande do Sul e têm suas obras editadas em Porto Alegre ou em outras cidades do estado, que já oferece todas as condições para desenvolver um trabalho gráfico.

É interessante ressaltar que essas obras recebem cuidados semelhantes àqueles que Monteiro Lobato dedica a seus livros, pois existe uma preocupação com a capa e a ilustração. Deste modo, o autor além de ter sua obra publicada pode escolher um ilustrador da competência de um Sotero Cosme, freqüentador do Café Colombo e autor dos desenhos de a Novena à Senhora da Graça de Theodomiro Tostes e de Mansamente de Paulo de Gouvêa.

Sotero já havia ilustrado algumas capas da Revista do Globo antes de 1930, quando vai a Paris a convite do Instituto Brasileiro do Café. Em Paris, vê publicada em edição luxuosa uma série de seus artigos.

Dante de Laytano em Colecionadores de Emoçöes destaca os trabalhos de ilustração de Carlos da Cunha para as obras de Dámaso Rocha, Telmo Vergara, Erico Verissimo e Ernani Fornari, e de Belanca nas obras de Ernani Fornari, Athos Damasceno e Raul Bopp entre outros.

Porto Alegre já possui, na década de 20, pintores e desenhistas de projeção, como Sotero Cosme, Hélio Seelinger, Leibindo Ferraz, João Fahrion, Oscar Boeira, João Faria Viana, Francis Pelicheck, José Rasga- 
do Filho e Ernst Zeuner. Possui, como se demonstrou, livrarias importantes, cinemas, jornais e uma movimentada vida intelectual.

O Centro de Porto Alegre abriga cafés e confeitarias por onde circulam, entre tantos freqüentadores, grupos de intelectuais.

A Livraria do Globo surge nesse cenário, aproveitando-se das condições favoráveis ao desenvolvimento de uma casa editora.

A cidade possui a mão-de-obra qualificada e a "disponibilidade revolucionária", como diria Mário de Andrade, para sustentar um investimento mais arrojado no mundo dos livros.

O desenvolvimento do processo de industrialização, ocorrido no Brasil deste século, é fator fundamental para a compreensão da indústria cultural e de livros. Tal processo vem acompanhado, na década de $30 \mathrm{da}$ ascensão de Getúlio Vargas, que ao inaugurar um estilo de política dependente da participação das massas, estimula a radiodifusão e o desenvolvimento do cinema nacional, do disco, da imprensa e do livro.

Este impulso incrementa a indústria cultural e os meios de comunicação de massas, cujos alicerces o próprio processo de industrialização já havia lançado.

Anteriormente, no entanto, já existe indústria de livros no Brasil. Suas demandas dependem das exigências de um escasso público leitor e do ensino público e privado, cujo material didático procede de algumas editoras. Essa indústria de livros, existente no século passado, e dependente da européia na medida em que de lá vem grande parte das obras já impressas e prontas para a comercialização, mesmo aquelas de autores nacionais.

No Brasil, do século passado, alguns livreiros tornam-se famosos editores, como os irmãos Garnier e os Laemmert. Na virada do século a Francisco Alves firma-se como a mais conhecida casa editora brasileira situada, assim como as outras no Rio de Janeiro.

Na década de 20, porém, São Paulo torna-se o principal pólo da produção de livros no momento em que Monteiro Lobato edita sua primeira obra - Urupês - e prepara-se para revolucionar, com seus métodos ousados, o mundo das edições no Brasil. A editora por ele fundada dá origem à Companhia Editora Nacional.

Depois que Monteiro Lobato se apropria das condições favoráveis de industrialização para montar uma empresa dependente de capital, mão-de-obra e mercado local, outras grandes casas editoras como a Brasiliense, José Olympio, Livraria Martins Editora, Civilização Brasileira desenvolvem-se e originam um moderno mercado editorial. 
Em dezembro de 1983, Laudelino Pinheiro de Barcellos, natural de Viamão, transfere-se para Porto Alegre e abre, na Rua da Praia, uma papelaria com o nome de Livraria do Globo, de L. P. Barcellos \& Cia.

A pequena livraria logo transforma-se em tipografia, fabricando livros em branco para a escrita de outras firmas. Em 1890, aumentando seus negócios, contrata o menino José Bertaso que tinha então 12 anos para ajudá-lo na limpeza, caixa e balcão da livraria.

José Bertaso permanece na livraria durante toda a sua vida. Passa de servente a caixeiro, chefe de loja, administrador das oficinas, gerente, interessado sócio e, em 1918, proprietário. Quando falece, em 1948, deixa um complexo empresarial que compreende uma importante livraria com filiais em Santa Maria, Rio Grande, Pelotas, escritórios no Rio de Janeiro e São Paulo e representantes em quase todas as capitais brasileiras. Possui instalações de varejo, depósitos e oficinas, um número significativo de funcionários, uma publicação semanal, a Revista do Globo, enfim, um patrimônio que, antes de mais nada, leva a marca Globo.

De todo esse patrimônio destaca-se a Secção Editora que por volta de 1930 começa a operar como um departamento especializado da firma Barcellos, Bertaso \& Cia. e em 1948, transforma-se em Editora Globo, filial da Livraria do Globo S.A. Mais tarde, em 1956, a Editora Globo torna-se uma sociedade anônima associada à Livraria do Globo S.A., em cujas oficinas gráficas continuaram a ser impressas as obras planejadas pela editora.

Mas é bem antes, em 1916, que a Globo lança o primeiro grande empreendimento da livraria como casa editora-o Almanaque do Globo. João Pinto da Silva, nome de prestígio entre os intelectuais de Porto Alegre, e Mansueto Bernardi, italiano de nascimento que viera morar no Rio Grande do Sul, são contratados para orientar a edição do almanaque.

Afirma um relatório da Livraria do Globo a respeito dessa contratação:

"(...) Em torno desses dois espíritos de escol, começaram a gravitar os jovens poetas e escritores do Rio Grande do Sul. Além disso, o pós-guerra havia empurrado para a América um expressivo contingente de técnicos e artistas europeus, de várias especialidades, e dentre estes tocou para o Rio Grande do Sul receber Karl Ernst Zeuner, desenhista, portador de enorme experiência junto às principais gráficas alemãs. Contratado pela Globo, ele também terminaria atraindo a atenção de jovens discípulos. Principalmente aos 
sábados à tarde - quando do encerramento do expediente comercial da semana - a loja da Rua da Praia tornara-se um importante ponto de encontro de intetectuais, artistas plásticos, políticos e profissionais liberais simpáticos à causa da Cultura. ${ }^{1}$

Mansueto Bernardi atua como administrador e divulgador intelectual da secção de obras e edições de 1918 a 1930, justamente o período em que a Livraria do Globo começa a editar autores sul-rio-grandenses, como Augusto Meyer, Dyonélio Machado, Ruy Cirne Lima, Paulo de Gouvêa e Vargas Netto.

Em levantamento feito no Correio do Povo, constata-se que a partir de 1926 começam a aparecer sistematicamente anúncios das publicações da Globo. Os comentários a respeito das obras são assinados por Paulo Arinos. Em 1927, surgem os primeiros anúncios pagos pela editora, cuja marca é um repetido elogio ao trabalho de edição (junho de 1926 a dezembro de 1927).

O Diário de Notícias também publica importantes notas relativas à atividade editoral da livraria:

"Da Livraria do Globo, o importante e modelar estabelecimento gráfico já tâo conhecido saiu a maioria das ediçōes já aparecidas no Estado. O nosso mercado editorial está por isso na dependência quase exclusiva de seus prelos. Esta dependência tem sido, é justo reconhecer mais uma vez, proveitosíssima, porém, ao desenvolvimento cultural do Rio Grande do Sul. Sem contarmos com uma empresa nas condições da Livraria do Globo talvez não fosse possível o surto literário que tornou rapidamente conhecido alguns escritores de maior merecimento da nova geração". ${ }^{2}$

1 Livraria do Globo: Relatório da Diretoria. 100 anos: 1883-1983. Porto Alegre, Globo, 1983, s/p. Em 1924 foi construído um edifício de vários andares no local do prédio anterior. Este prédio, localizado na Rua da Praia, ainda abriga as instalaçōes da Livraria, apesar de ter passado por uma reforma que o transformou, na atualidade, em um centro comercial.

2 Diário de Notícias, Porto Alegre, 1 de janeiro de 1929, p. 17. Nesta coluna aparece a seguinte relação das obras editadas: Júlio de Castilhos, por Othelo Rosa; Gado Xucro e Tu por Vargas Netto; Colônia Z de Rui Cirne Lima; No Galpão (3. ed.) por Darcy Azambuja; Evoluçāo das Idéias de Renato Correia de Oliveira; Novena à Senhora da Graça por Theodomiro Tostes; Trabalhos e Costumes Gaúchos, de S. Sá Brito; Giraluz e Duas Oraçôes por Augusto Meyer; Três Poemas Franciscanos por Mansueto Bernardi; Trem da Serra por Ernani Fornari; Traços Eternos do Rio Grande por Fernando Osório; A Terra Gaúcha por Henrique de Casaes; Vocabulário Gaúcho (2. ed.) por Roque Callage; Liçōes de Clínica Médica, Dr. Heitor Annes Dias; $O$ 
As obras editadas até então são de autores gaúchos, como os do Grupo do Café Colombo que saem do ineditismo com seus livros de prosa e verso. A livraria, nesse período, também edita obras técnicas, basicamente ligadas à área da saúde e do direito, além de demonstrar uma preocupação com a história, a terra, as tradiçóes e os costumes rio-grandenses.

No ano de 1929, a Livraria do Globo, além de intensificar a produção de livros, passa a investir no ambicioso projeto de lançar quinzenalmente uma revista. Ela é assim anunciada pelo Correio do Povo:

"Circulará sábado próximo, 5 do corrente (janeiro) a Revista do Globo, sob a orientação do escritor Mansueto Bernardi.

Contando com um brilhante corpo redatorial e com a colaboração dos mais conhecidos homens de letras do Estado, a nova publicação que será quinzenal e de luxo, destina-se a um completo êxito. $O$ fato de ser uma edição da Livraria do Globo, assegura-lhe, desde logo, uma vida vitoriosa.

O primeiro número da Revista do Globo que está sendo esperado com viva e natural ansiedade, apresentar-se-á variadíssimo e será uma mostra da sua atuação na imprensa desta capital." ( 3 de janeiro de 1929, p. 4)

Uma vez delineado o quadro pode-se projetar nele a Secção Editora da Livraria do Globo nos idos de 1930, e as razões que a levaram a tornar-se uma grande casa editora.

A Editora Globo surge nos anos 30 na esteira das grandes editoras brasileiras, com a diferença de que sua sede fica num estado periférico e geograficamente distante do tradicional centro de produção e consumo de livros no Brasil.

Apesar dessa distância e mesmo por esta razão, o Rio Grande do Sul transforma-se no terceiro centro industrial da Federação. Aqui as condições para o desenvolvimento de uma empresa industrial voltada aos livros também são favoráveis porque:

Orçamento Rio-Grandense de Fernando Caldas; O Estado Sanitário do Rio Grande do Sul, do Dr. Castro Carvalho; Notas para a História de Porto Alegre por Gastão Hasslocher Mazeron; Novo Dicionário Nacional, do Pe. Carlos Teschauer; Canção das Águas de Antonio Siqueira; Manual de Teoria e Prática do Processo Penal (3. ed., 4 v.), do Dr. Inocêncio Borges da Rosa; Assuntos Militares do Coronel Álvaro de Alencastro; Da Açāo Executiva por Odorico da Silva Camargo. 
$1^{\circ}$ - trata-se de um estado cuja tradição industrial está bastante definida, pelas suas necessidades de abastecimento, e tem Porto Alegre como principal pólo produtor;

$2^{\circ}$ - o RS, segundo fontes oficiais, é o Estado que possui a maior taxa de indivíduos alfabetizados do Brasil, o que significa, entre outras coisas, a existência de virtuais leitores;

$3^{\circ}$ - experiências no campo da editoração e publicação já haviam sido feitas no século XIX e algumas livrarias da capital editavam livros, o que significa uma certa experiência neste campo da indústria;

$4^{\circ}$ - Porto Alegre é um importante centro cultural que abriga intelectuais atuantes, muitos escritores com obras prontas para serem editadas, pintores e desenhistas aptos para fazer capas de livros, tradutores familiarizados com outros idiomas e até talentosos editores que se assenhoriam das condições propícias para trazer ao público brasileiro, em português, obras que até então somente eram lidas pelos conhecedores de outros idiomas;

$5^{\circ}$ - além do que já foi citado, constata-se uma disposição a aceitação de autores novos, abrindo, deste modo, um espaço para a divulgação de obras vindas dos Estados Unidos. De lá vem também um novo estilo de vida, marcado pelos sintomas da modernidade e pelas sedutoras novidades como e o caso do cinema de ação, objeto de crescente interesse dos brasileiros.

A Secção Editora até 1930 tem uma limitada produção de livros ligados, em sua maioria, a autores gaúchos, além de algumas traduções. A partir de então, inicia-se uma fase em que as traduções tornam-se a peça mais importante da Secção. As obras selecionadas, quase todas voltadas para a literatura popular, são distribuídas em coleções que ao serem divulgadas pela imprensa, pela Revista do Globo e por outros esquemas de publicidade da empresa, tornam-se rapidamente conhecidas do público leitor.

Alguns autores, como Karl May, Edgard Wallace e Agatha Christie, entre muitos outros, transformam-se no dizer de Érico Veríssimo numa "argamassa popularesca", que toda editora deve ter, se quiser manter a presença de outros autores mais eruditos.

A presença de Henrique Bertaso e Érico Veríssimo, o contato destes com revistas especializadas, com intelectuais de prestígio como é 
o caso de Augusto Meyer, com feiras e com a experiência e o suporte financeiro que a Livraria do Globo dá a seus projetos, permitem-lhes editar, depois de 1937, alguns dos mais importantes nomes da literatura universal. Até a literatura e o pensamento da antigüidade clássica fazemse presentes nessa lista que se torna o maior indicador do sucesso da Secção Editora.

Sucesso aqui não está sendo relacionado ao volume de vendas e sim à aquisição de importantes direitos autorais e à capacidade de traduzir, ilustrar e colocar a obra no mercado. A partir dos dados coletados durante a pesquisa, fica difícil avaliar se esse volume de edições vinha acompanhado de vendas.

De qualquer forma, a Globo nos dez anos posteriores a 1938 desenvolve uma enorme capacidade produtiva que a transforma numa das três maiores editoras do país.

Suas traduções possuem alta qualidade e altos custos, atestando, através do tratamento dado às obras, o desejo de seus editores de fazer da Globo um dos mais prestigiados nomes do Brasil. Este prestígio cresce com a tradução de Honoré Balzac, Marcel Proust, James Joyce, Virgínia Woolf, Leon Tolstoi, William Faulkner, Andre Gide, Bernard Shaw, Aldous Huxley, Somerset Maugham - a lista é bastante longa - com a publicação da Encilopédia Brasileira Globo e com o sucesso nacional dos livros de Érico Veríssimo de Olhai os Lírios do Campo (1938) ao aparecimento do último volume de O Tempo e o Vento (1963).

Até 1947 a atividade editorial - traduções, confecções de enciclopédias, organização de coleções - é incessante. Depois desta data, os registros das edições começam a diminuir e, segundo os próprios editores, a atenção se volta para os livros técnicos, livros-ferramentas, que atendem as novas exigências da especialização profissional; para os livros de Érico Veríssimo, para a Enciclopédia Globo e para os cursos de línguas estrangeiras, mais precisamente o britânico Linguaphone, à base de discos e fitas sonoras.

Depois de 1948, as grandes obras, tão caras a Henrique Bertaso e a Érico Veríssimo, começam a desaparecer do Livro de Registros, o volume das edições voltadas para o campo literário diminui, configurando a nova política editorial da empresa.

Neste mesmo ano a Livraria perde seu diretor, José Bertaso. Este momento significa muito para todos os que convivem com este homem que é um exemplo de empresário exigente, de temperamento explosivo, dono de inquestionável tino comercial e de uma sensibilidade natural que 
lhe permitiu compreender e até apoiar os investimentos de seu filho Henrique e dos assessores quase sempre insaciáveis.

Os herdeiros e a nova administração decidem pela transformação da empresa em sociedade anônima - Livraria do Globo S.A. - da qual a Editora Globo torna-se uma filial. Esta divisão se consolida em 1956 quando a empresa passa a ser Livraria do Globo S.A. e Editora Globo S.A. e, em 1986, o respeitável acervo de 2.830 títulos passou a ser administrado pelas Organizações Globo.

Pelo visto mais uma vez será construída em cima de uma "argamassa popularesca", revistas e fascículos, uma nova empresa que para se tornar legítima aos olhos da "intelligentsia" brasileira deve fazer o que Érico e Henrique Bertaso fizeram há 50 anos.

\section{Referências bibliográficas}

ANUÁRIO DO ESTADO DO RIO GRANDE DO SUL para o ano de 1914 da Graciano A. Azambuja. Porto Alegre: Krahe \& Cia, sucessores de Glundach e Krahe, 1913. CORREIO DO POVO, 1920 a 1935.

DIÁRIO DE NOTÍCIAS, 1929 e 1930.

GOUVÊA, Paulo de. O Grupo. Porto Alegre: Movimento/IEL, 1976.

LAYTTANO, Dante de. Colecionadores de emoções. Porto Alegre: Globo, 1934.

LIVRARIA DO GLOBO. Relatório da Diretoria. 100 Anos: 1883-1983. Porto Alegre: Globo, 1983, s.p.

MEYER, Augusto. No tempo da flor. Rio de Janeiro: Ediçōes O Cruzeiro, 1966.

PIMENTEL, Fortunato. Aspectos gerais de Porto Alegre. s.e. 1945, v. 1

REVISTA DO GLOBO. 1929 a 1940.

SINGER, Paul. Desenvolvimento econômico e evoluçāo urbana. São Paulo: Nacional/USP, 1968.

SPALDING, Watter. Construtores do Rio Grande. Porto Alegre: Sulina, 1969. v. 1. 